\title{
The neural underpinnings of vicarious experience
}

\author{
Bernadette M. Fitzgibbon ${ }^{1}{ }^{*}$, Jamie Ward $^{2}$ and Peter G. Enticott ${ }^{3}$ \\ ${ }^{1}$ Monash Alfred Psychiatry Research Center, Central Clinical School, Monash University, Melbourne, VIC, Australia \\ ${ }^{2}$ Department of Psychology, University of Sussex, Brighton, UK \\ ${ }^{3}$ Cognitive Neuroscience Unit, School of Psychology, Deakin University, Melbourne, VIC, Australia \\ ${ }^{*}$ Correspondence: bernadette.fitzgibbon@monash.edu
}

Edited and reviewed by:

Hauke R. Heekeren, Freie Universität Berlin, Germany

Keywords: social neuroscience, social cognition, mirror neurons, empathy, touch, pain, personality, vicarious experience

In recent decades there has been an explosion of empirical research into the social cognitive processes that underlie our social interactions. Coinciding with, or perhaps driving, the interest within this area is the development of modern neuroscientific techniques bringing real world experiences into the laboratory to produce biological models of how we experience and interact with other people.

In this research topic, we present a range of expert manuscripts that focus on one primary aspect of social cognition: the ability to recognize, understand and, in some cases, "feel" the experience of another person. To date, neuroscience research in this area has identified shared neural networks whereby we process another's action, emotion or sensation through overlapping brain regions as if we were carrying out that same action or experiencing that same emotion or sensation. Intriguingly, this research has shown that such vicarious activation of brain networks can span from an automatic and unconscious process through to an overt experience of the emotion or sensation of that observed in another person.

By investigating vicarious processes as well as exploring the influence of interpersonal characteristics such as empathy, we are taking a step toward better understanding the relationship between the social brain and social behavior. This includes the decision to make a pro-social response vs. fleeing potentially dangerous, or even socially awkward situations, such as witnessing another person embarrass themselves. Moreover, this research area has substantial implications for understanding disease and improving treatment options for people who experience psychiatric or neurological illness including autism spectrum disorder, where impairment in aspects of social functioning is a key feature. However, even beyond disorders where social function may be diagnostic, social impairments and difficulties in social relationships can have substantial functional consequences, as is often reported in illnesses such as depression and schizophrenia. Ultimately, understanding the neurobiology of social processes will provide the platform for targeted and appropriate treatment interventions.

In the work that follows, this research topic brings together a number of opinions, perspectives, hypotheses and theories, general commentaries, reviews and original research articles. Several key themes can be identified ranging from:

(1) Definitional considerations including the distinction between vicarious and empathic experiences (Paulus et al.,
2013), and why overt vicarious experiences may not represent a new form of synaesthesia, where sensory input in one domain results in a sensory experience in another (Rothen and Meier, 2013);

(2) Exploration of vicarious shared neural experiences in the general population from physical touch and injury (Bufalari and Ionta, 2013) through to ostracism (Wesselmann et al., 2013) and how vicarious experience may differ between people according to attention (Morelli and Lieberman, 2013), interpersonal and personality differences (Schaefer et al., 2013; Vandenbroucke et al., 2013) such as empathy, and the influence of psychopathic (Marcoux et al., 2013) or autistic (Cooper et al., 2013) traits. Additional modulating factors of vicarious experience are also considered including expertise seen in physicians (Newton, 2013), the influence of the mother-child bond (Manini et al., 2013), the experimental administration of oxytocin and the effect of visual orientation (i.e., self vs. other) (Burgess et al., 2013).

(3) The investigation of atypical vicarious experiences in the general population such as shared touch (Banissy and Ward, 2013) and pain and how feeling the pain of others may be linked with self-other confusion and prior pain experience (Derbyshire et al., 2013). Through to a physiological study exploring the experience of misophonia, describing a sensitivity to sound that can substantially limit ones ability to interact with others (Edelstein et al., 2013), and a commentary of why vicarious perception may drive contagious scratching (Ward et al., 2013);

(4) The discussion of vicarious experiences in atypical populations including evidence against an impairment in shared neural networks in ASD (Enticott et al., 2013) and an argument for how models of vicarious pain experience may help us understand the relationship between core ASD symptoms better (Fitzgibbon et al., 2013);

(5) Finally, the role of vicarious experience including vicarious motor system activation in understanding the behaviors of others (Avenanti et al., 2013) and how group membership may influence such processing and influence how we interact with others (Eres and Molenberghs, 2013).

Taken together, this research topic presents cutting edge research in a growing field which, while by no means definitive, represents exciting developments in the neurobiology underlying sharing experiences with others. 


\section{ACKNOWLEDGMENTS}

Bernadette M. Fitzgibbon is supported by a National Health and Medical Research Council (NHMRC, Australia) early career fellowship [GNT1070073]. Peter G. Enticott is supported by a NHMRC Career Development Fellowship [GNT1052073].

\section{REFERENCES}

Avenanti, A., Candidi, M., and Urgesi, C. (2013). Vicarious motor activation during action perception: beyond correlational evidence. Front. Hum. Neurosci. 7:185. doi: 10.3389/fnhum.2013.00185

Banissy, M. J., and Ward, J. (2013). Mechanisms of self-other representations and vicarious experiences of touch in mirror-touch synesthesia. Front. Hum. Neurosci. 7:112. doi: 10.3389/fnhum.2013.00112

Bufalari, I., and Ionta, S. (2013). The social and personality neuroscience of empathy for pain and touch. Front. Hum. Neurosci. 7:393. doi: 10.3389/fnhum.2013.00393

Burgess, J. D., Arnold, S. A., Fitzgibbon, B. M., Fitzgerald, P., and Enticott, P. G. (2013). A transcranial magnetic stimulation study of the effect of visual orientation on the putative human mirror neuron system. Front. Hum. Neurosci. 7:679. doi: 10.3389/fnhum.2013.00679

Cooper, N. R., Simpson, A., Till, A., Simmons, K., and Puzzo, I. (2013). Beta event-related desynchronization as an index of individual differences in processing human facial expression: further investigations of autistic traits in typically developing adults. Front. Hum. Neurosci. 7:159. doi: 10.3389/fnhum.2013.00159

Derbyshire, S. W., Osborn, G. J., and Brown, S. (2013). Feeling the pain of others is associated with self-other confusion and prior pain experience. Front. Hum. Neurosci. 7:470. doi: 10.3389/fnhum.2013.00470

Edelstein, M., Brang, D., Rouw, R., and Ramachandran, V. S. (2013). Misophonia: physiological investigations and case descriptions. Front. Hum. Neurosci. 7:296. doi: 10.3389/fnhum.2013.00296

Enticott, P. G., Kennedy, H. A., Rinehart, N. J., Bradshaw, J. L., Tonge, B. J., Daskalakis, Z. J., et al. (2013). Interpersonal motor resonance in autism spectrum disorder: evidence against a global "mirror system" deficit. Front. Hum. Neurosci. 7:128. doi: 10.3389/fnhum.2013.00218

Eres, R., and Molenberghs, P. (2013). The influence of group membership on the neural correlates involved in empathy. Front. Hum. Neurosci. 7:176. doi: 10.3389/fnhum.2013.00176

Fitzgibbon, B. M., Segrave, R. A., Fitzgerald, P. B., and Enticott, P. G. (2013). Can studies of pain help to bridge the gap between sensory and social impairments in autism? Front. Hum. Neurosci. 7:103. doi: 10.3389/fnhum.2013.00103

Manini, B., Cardone, D., Ebisch, S., Bafunno, D., Aureli, T., and Merla, A. (2013). Mom feels what her child feels: thermal signatures of vicarious autonomic response while watching children in a stressful situation. Front. Hum. Neurosci. 7:299. doi: 10.3389/fnhum.2013.00299
Marcoux, L., Michon, P., Voisin, J., Lemelin, S., and Jackson, P. L. (2013). The modulation of somatosensory resonance by psychopathic traits and empathy. Front. Hum. Neurosci. 7:274. doi: 10.3389/fnhum.2013.00274

Morelli, S. A., and Lieberman, M. D. (2013). The role of automaticity and attention in neural processes underlying empathy for happiness, sadness, and anxiety. Front. Hum. Neurosci. 7:160. doi: 10.3389/fnhum.2013.00160

Newton, B. W. (2013). Walking a fine line: is it possible to remain an empathic physician and have a hardened heart? Front. Hum. Neurosci. 7:223. doi: 10.3389/fnhum.2013.00233

Paulus, F. M., Müller-Pinzler, L., Westermann, S., and Krach, S. (2013). On the distinction of empathic and vicarious emotions. Front. Hum. Neurosci. 7:196. doi: 10.3389/fnhum.2013.00196

Rothen, N., and Meier, B. (2013). Why vicarious experience is not an instance of synesthesia. Front. Hum. Neurosci. 7:128. doi: 10.3389/fnhum.2013.00128

Schaefer, M., Rotte, M., Heinze, H., and Denke, C. (2013). Mirror-like brain responses to observed touch and personality dimensions. Front. Hum. Neurosci. 7:227. doi: 10.3389/fnhum.2013.00227

Theodoridou, A., Rowe, A. C., and Mohr, C. (2013). Men perform comparably to women in a perspective taking task after administration of intranasal oxytocin but not after placebo. Front. Hum. Neurosci. 7:197. doi: 10.3389/fnhum.2013.00197

Vandenbroucke, S., Crombez, G., Van Ryckeghem, D. M. L., Brass, M., Van Damme, S., and Goubert, L. (2013). Vicarious pain while observing another in pain: an experimental approach. Front. Hum. Neurosci. 7:265. doi: 10.3389/fnhum.2013.00265

Ward, J., Burckhardt, V., and Holle, H. (2013). Contagious scratching: shared feelings but not shared body locations. Front. Hum. Neurosci. 7:122. doi: 10.3389/fnhum.2013.00122

Wesselmann, E. D., Williams, K. D., and Hales, A. H. (2013). Vicarious ostracism. Front. Hum. Neurosci. 7:153. doi: 10.3389/fnhum.2013.00153

Conflict of Interest Statement: The authors declare that the research was conducted in the absence of any commercial or financial relationships that could be construed as a potential conflict of interest.

Received: 08 May 2014; accepted: 15 May 2014; published online: 03 June 2014. Citation: Fitzgibbon BM, Ward J and Enticott PG (2014) The neural underpinnings of vicarious experience. Front. Hum. Neurosci. 8:384. doi: 10.3389/fnhum.2014.00384 This article was submitted to the journal Frontiers in Human Neuroscience.

Copyright (c) 2014 Fitzgibbon, Ward and Enticott. This is an open-access article distributed under the terms of the Creative Commons Attribution License (CC BY). The use, distribution or reproduction in other forums is permitted, provided the original author(s) or licensor are credited and that the original publication in this journal is cited, in accordance with accepted academic practice. No use, distribution or reproduction is permitted which does not comply with these terms. 